\title{
Pergeseran dan Pemertahanan Bahasa Ibu Dalam Ranah Rumah Tangga Migran di Kota Semarang \\ Mujid F Amin dan Suyanto
}

\author{
Fakultas Ilmu Budaya Universitas Diponegoro \\ Email: moejid70@gmail.com dan suyanto@undip.ac.id
}

\begin{abstract}
This study aims to explain the pattern of language selection in speech acts between Indonesian language and mother tongue of migrants; Explaining the migration process of migrant language; Identify and explain the pattern of migrant language shift in Semarang City; and explains the contributing factors of shifting and maintaining the language of migrants. Sampling using cluster sampling technique followed by random sampling. Data collection using observation or referring method, stereo interview, and in-depth interview. Data analysis used descriptive statistics (single and cross frequency distribution table) and qualitative descriptive. Qualitative analysis by means of categorical analysis followed by theoretical meanings and conclusions. The results of this study indicate a shift in mother tongue in the domestic realm. Most of the migrants in Semarang City use Bahasa Indonesia more often than their mother tongue. However, there are some migrants who still maintain their mother tongue among the traditional migrants residing in the kampong area. In the family domain, married migrants whose mother tongue is the same as the mother tongue (husband or wife), are more likely to use a combination of mother tongue and Indonesian to communicate in both family and family affairs.
\end{abstract}

Keywords: mother tongue, language shift, language selection, maintaining the language, domestic realm

\section{Intisari}

Penelitian ini bertujuan menjelaskan pola pemilihan bahasa dalam tindak tutur antara bahasa Indonesia dan bahasa ibu kaum migran; menjelaskan proses pergeseran bahasa kaum migran; mengidentifikasi dan menjelaskan pola pergeseran bahasa kaum migran di Kota Semarang; dan menjelaskan faktor penyebab pergeseran dan pemertahanan bahasa kaum migran. Pengumpulan data menggunakan metode observasi atau simak, wawancara stertruktur, dan wawancara mendalam. Analisis data menggunakan statistik deskriptif (tabel distribusi frekuensi tunggal dan silang) dan deskriptif kualitatif. Analisis kualitatif dengan cara analisis kategoris yang dilanjutkan pemaknaan secara teoretik serta penyimpulan. Hasil penelitian ini menunjukkan adanya pergeseran bahasa ibu dalam ranah rumah tangga. Sebagian besar migran di Kota Semarang lebih sering menggunakan bahasa Indonesia dibandingkan dengan bahasa ibu mereka. Akan tetapi, ada beberapa migran yang masih mempertahankan bahasa ibunya yaitu pada kalangan migran tradisional yang bertempat tinggal di daerah perkampungan. Dalam ranah keluarga, migran berstatus menikah yang bahasa ibunya sama dengan bahasa ibu pasangan (suami atau istri), lebih sering menggunakan kombinasi antara bahasa ibu dan bahasa Indonesia untuk berkomunikasi dalam hal urusan keluarga maupun selain urusan keluarga.

Kata kunci : bahasa ibu, pergeseran, pemilihan bahasa, pemertahanan bahasa ibu, ranah keluarga. 


\section{Pendahuluan}

Dalam proses migrasi penduduk pada umumnya lebih dilihat sebagai fenomena ekonomi karena tujuan utama penduduk (penutur bahasa) melakukan migrasi adalah untuk memenuhi berbagai kebutuhan bersifat material, selain sosial, psikologis, dan politis (Mantra, 2000; 2015). Akan tetapi, satu fenomena yang seringkali terabaikan dalam kaitan migrasi penduduk (yang juga sebagai penutur bahasa) adalah faktor budaya, terutama tentang kebahasaan. Dari aspek kebahasaan, penduduk melakukan migrasi tidak selamanya pada daerah tujuan yang memiliki bahasa ibu yang sama, tetapi seringkali ke daerah tujuan atau masyarakat bahasa yang berbeda, baik dalam tataran dialek maupun bahasa. Dengan hidup di lingkungan yang berbahasa ibu berbeda akan menuntut pemakaian bahasa yang berbeda daripada bahasa ibu di daerah asalnya. Ketika hidup dalam kondisi demikian, migran tersebut dihadapkan pada beberapa pilihan yaitu menggunakan bahasa nasional (dalam konteks Indonesia adalah bahasa Indonesia), bahasa ibunya jika berkomunikasi dengan penutur yang memiliki bahasa ibu yang sama, atau beradaptasi menggunakan bahasa ibu (bahasa daerah) daerah tujuan migrasi. Dinamika pemakaian bahasa akan lebih kompleks lagi bagi migran generasi berikutnya, kedua, ketiga dan seterusnya. Bagi migran generasi kedua yang dilahirkan di daerah tujuan pada umumnya akan menjadi penutur bilingual atau multilingual antara bahasa nasional (bahasa Indonesia dalam konteks Indonesia) dan bahasa ibu daerah tujuan serta kemungkinan masih menguasai bahasa ibu orang tuanya. Generasi ketiga migran sudah menjadi monolingual, yakni hanya menguasi bahasa daerah (Negara) tujuan atau dalam konteks Indonesia kemungkinan hanya menguasai bahasa daerah tujuan dan tentu bahasa nasional (Indonesia) (cf.Sumarsono, 2013; Chaer dan Agustina,2010).

Dengan adanya berbagai kemungkinan pemakaian bahasa tersebut di atas, artinya terjadi adanya proses pemilihan bahasa dalam tindak tutur. Adanya alternatif pilihan bahasa yang digunakan inilah bagi diri penutur terjadi proses pergeseran bahasa atau pemertahanan bahasa bergantung pilihan bahasa yang digunakan. Pemilihan bahasa ini seringkali lebih ditentukan oleh kebutuhan praktis, yakni adanya tuntutan kebutuhan harus menggunakan bahasa yang dipergunakan daerah tujuan. Walau demikian, karena penutur tersebut memiliki bahasa ibu yang telah dipergunakan sejak lahir misalnya, 
dalam situasi tertentu juga akan menggunakan bahasa ibunya. Dalam konteks ini, berbagai faktor berpengaruh terhadap pemilihan bahasa, seperti partisipan, situasi, ranah, dan tujuan (Fishman, 1972; Sumarsono, 2013, Chaer dan Agustina, 2010). Apabila berkomunikasi dengan mitra tutur yang berasal dari daerah yang sama, maka pilihan bahasa yang digunakan adalah bahasa ibu atau nasional, jika dengan partisipan yang berbahasa ibu berbeda kemungkinan pilihannya adalah bahasa nasional (bahasa Indonesia) atau salah satu bahasa ibu partispan jika keduanya menguasai bahasa ibu masing-masing atau salah satunya. Situasi juga ikut berperan menentukan pilihan bahasa, selain ranah dan tujuan.

Berbagai studi terdahulu menunjukkan bahwa kajian pergeseran dan pemertahanan bahasa pada umumnya mengkonsentrasikan pada bahasa tertentu: Jawa, sunda, Bugis, Banjar, dan sebagainya (Mardikantoro, 2007; Jamzaroh, dkk, 2010; Yuliawati, 2008). Dengan kata lain, berbagai studi terdahulu lebih bersifat mikro, sedangkan kajian bersifat makro yakni pergeseran dan pemertahanan bahasa dalam satu masyarakat bilingual atau multilingual, seperti kota-kota besar di Indonesia, seperti masyarakat Kota Semarang belum pernah dikaji. Karena hal itu, rencana penelitian ini akan mengkaji fenomena pergeseran dan pemertahana bahasa-bahasa ibu di kota Semarang, khususnya pada ranah keluarga.

Dalam penelitian ini masalah yang dikaji yaitu bagaimana pergeseran dan pemertahanan bahasa ibu bagi migran di kota Semarang pada ranah keluarga. Tujuan dari penelitian ini untuk mengetahui bagaimana pergeseran dan pemertahanan bahasa ibu bagi migrant di kota Semarang khususnya pada ranah keluarga.

\section{Pemilihan Bahasa}

Pemilihan bahasa tidak terlepas dari fenomena situasi diglosia. Dalam kasus Indonesia, pembagian fungsi kemasyarakatan antara bahasa Indonesia dan bahasa daerah dapat dilihat dari indikator kelas sosial, usia, pola perkawinan, lokasi pemakaian, situasi pemakaian (Abdullah dalam Wijana, 2013: 33). Kelas sosial semakin tinggi, usia muda, perkawinan campuran, penduduk yang tinggal di perkotaan, dan situasi formal cenderung menggunakan bahasa Indonesia, sementara kelas sosial semakin rendah, usia tua, perkawinan satu etnis/bahasa ibu, penduduk pedesaan, dan dalam situasi informal cenderung menggunakan bahasa daerah.Demikian juga studi dalam skala global yang dilakukan oleh Mackey (Wijana, 2013:37) menjelaskan bahwa kekuatan bahasa dapat 
diukur dengan indikator demografi, persebaran, ekonomi, ideologi, dan kultural. Semakin banyak jumlah penutur suatu bahasa dan persebaran tempat tinggal semakin luas (mendunia), GNP Negara pemilik bahasa tersebut semakin tinggi, maka bahasa tersebut semakin mendominasi peran dalam skala global. Situasi diglosia dan dominasi bahasa tersebut berkaitan dengan pemilihan bahasa.

Dalam masyarakat bilingual atau multilingual, penutur ketika berbicara dengan menggunakan dua bahasa atau lebih dan harus memilih yang mana harus dipakai (Fasold, 1984:180). Dalam pemilihan bahasa, terdapat tiga jenis pilihan: (1) dengan alih kode (code switching) yaitu menggunakan suatu bahasa pada suatu domain dan menggunakan bahasa lain pada domain yang lain; (2) dengan campur kode (code mixing) yaitu menggunakan satu bahasa tertentu dengan dicampuri serpihan-serpihan bahasa lain; dan (3) dengan menggunakan sutu variasi dalam satu bahasa (variation within the same language).

Sementara itu, Fishman (dalam Chaer \& Agustina, 2010: 204) menjelaskan bahwa dalam mengkaji pemilihan bahasa dapat dilakukan berbasis domain (konteks institusional) tertentu, yang menunjukkan kecenderungan penutur memilih atau menggunakan satu variasitertentu daripada variasi lain. Domain merupakan konstelasi dari faktor lokasi, topik, dan partisipan. Dengan demikian, dikenal domain keluarga, tetangga, teman, transaksi, pemetintahan, pendidikan, dan sebagainya. Jika seorang penutur berbicara dalam lingkungan keluarga misalnya, maka dikatakan berada dalam domain keluarga. Analisis domain ini serin dikaitkan dengan analisis diglosia, sebab ada domain yang bersifat formal dan tidak formal. Dalam masyarakat yang bersifat diglosik, ragam bahasa yang digunakan untuk domain yang tidak formal biasanya bahasa ragam rendah (low language), sedangkan dalam domain yang bersifat formal dipakai bahasa ragam tinggi (high language). Karena iyulah, pemilihan satu bahasa atau ragam bahasa bergantung domainnya.

\section{Pergeseran Bahasa}

Pergeseran bahasa sebenarnya menyangkut masalah penggunaan bahasa oleh seorang penutur atau sekelompok penutur yang terjadi akibat perpindahan dari satu masyarakat tutur ke masyarakat tutur yang baru. Menurut Amar (2004), proses pergeseran bahasa merupakan satu peristiwa sejarah karena lambat laun bahasa ibu bagi kelompok penutur ini akan mengalami kepunahan sama sekali. Hal ini selaras dengan pendapat Mbete 
(2003: 14) bahwa pergeseran bahasa berawal dari penyusutan fungsi-fungsi dasarnya yang umumnya terjadi dalam rentang waktu yang lama dan perlahan-lahanmelampaui beberapa generasi.

Punahnya suatu bahasa ditandai dengan berkurangnya atau bahkan hilangnya bahasa lokal yang dipakai dalam pertuturan di dalam keluarga, misalnya antara orang tua dan anak-anak. terlebih lagi, hal itu ditandai dengan menghilangnya budaya dongeng, sirnanya kebiasaan bercerita kepada anak-anak sebelum tidur, dan tidak berfungsinya lembaga-lembaga tradisional sebagai benteng dan budaya dan tradisi (Mardikantoro, 2007: 43-44).

Pergeseran bahasa berarti, suatu guyup (komunitas, masyarakat bahasa) meninggalkan suatu bahasa sepenuhnya untuk memakai bahasa lain. Bila pergeseran sudah terjadi, para warga guyup itu secara kolektif memilih bahasa baru (Sumarsono, 2013: 231).

Pergeseran bahasa biasanya terjadi di Negara, daerah, atau wilayah yang memberi harapan untuk kehidupan sosial ekonomi yang lebih baik sehingga mengundang imigran/transmigran untuk mendatanginya. Fishman (dalam Chaer dan Agustina, 2010: 144) telah menunjukkan terjadinya pergeseran bahasa para imigran di Amerika. Keturuanan ketiga atau keempat dari para imigran itu sudah tidak lagi mengenal bahasa ibunya (B-ib), dan malah telah terjadi monolingual bahasa Inggris (Bing).

\section{Metode Penelitian}

Data yang dibutuhan dalam penelitian ini adalah data sekunder dan primer. Data sekunder diperoleh dari BPS Kota Semarang, BPS Provinsi Jawa Tengah, dan kantor kelurahan sampel wilayah. Data yang akan dikumpulkan adalah jumlah dan komposisi penduduk menurut lapangan pekerjaan, jenis kelamin, tingkat pendidikan, dan disribusi tempat tinggal. Selain itu, diperoleh juga data tentang migrasi masuk di Kota Semarang berdasarkan jenis kelamin, tingkat pendidikan, pekerjaan, tempat tinggal, etnis, daerah asal, siklus generasi dalam tinggal di Semarang (berdasar tempat lahir), lama tinggal di Kota Semarang. Data primer meliputi data kuantitatif dan kualitatif. Data primer kuantitatif dijaring mengguankan wawancara terstruktur. Adapun pengumpulan data primer kualitatif dilakukan dengan metode simak atau observasi dan wawancara mendalam. 
Analisis data rencana studi ini menggunakan analisis kuantitatif dan kualitatif. Analisis kuantitatif menggunakan statistik deskriptif (tabel distribusi frekuensi tunggal dan silang). Analisis ini untuk menjelaskan kecenderungan, mean, median, dan modus. Selain itu, analisis deskriptif dipergunakan untuk mendeskripsikan distribusi aspek (variabel) demografi (umur, status kawin/status dalam keluarga, jenis kelamin, tempat lahir, riwayat migrasi) dan sosial ekonomi (tingkat pendidikan, peran sosial dalam masyarakat dan organisasi, pekerjaan, klaster tempat tinggal (perumahan, perkampungan), dan lama tinggal migran) yang kesemuanya itu terkait dengan aspek kebahasaan (pemilihan dan pergeseran bahasa ibu).Analisis kualitatif menggunakan analisis deskriptif, kategoris, dan pemaknaan teoretik. Analisis deskriptif ini untuk mendeskripsikan berbagai wujud tuturan yang menunjukkan pemilihan dan pergeseran dalam penggunaan bahasa ibu dengan bahasa yang lain. Analisis kualitatif ini merupakan triangulasi analisis data. Analisis deskriptif dilanjutkan dengan analisis kategoris yang dipergunakan untuk melakukan kategorisasi karakteristik demografi, sosial ekonomi, pemilihan dan pergeseran bahasa. Kategorisasi tersebut selanjutnya dimaknai secara teoretik menggunakan teori pemilihan, pergeseran, dan pemertahanan bahasa. Hasil kategorisasi itu pada giliran berikutnya dipergunakan untuk menjelaskan pola pemilihan dan pergeseran bahasa ibu. Berbagai kategorisasi dan pola pemilihan dan pergeseran bahasa ibu dapat untuk menjelaskan pemertahanan bahasa ibu kaum migran di Kota Semarang.

\section{Hasil Analisis}

Pergeseran dan pemertahanan bahasa ibu pada ranah keluarga dijelaskan sebagai berikut:

1. Bahasa Ibu Responden sama dengan Bahasa Ibu Suami/Istri

Berdasarkan sama atau tidaknya bahasa ibu responden dengan suami atau istri, sebanyak 67 responden atau 60,9 persen menjawab sama, sedangkan sisanya sebanyak 15 responden atau 13,6 persen menjawab berbeda. Dari hasil tersebut dapat dilihat bahwa kecenderungan pemertahanan bahasa ibu seharusnya semakin tinggi karena bahasa ibu responden sama dengan bahasa ibu dari suami atau istri responden. Akan tetapi, hal tersebut tidak dapat dijadikan patokan karena banyak faktor yang mempengaruhi pergesaran bahasa ibu, beberapa contohnya yaitu masuknya bahasa 
asing ke Indonesia dan gaya hidup masyarakat sekarang yang semakin modern termasuk dalam hal penggunaan bahasa.

2. Bahasa Komunikasi dengan Suami atau Istri untuk Urusan Keluarga

Dalam komunikasi sehari-hari dengan suami atau istri untuk urusan keluarga, seperti kegiatan dalam rumah tangga dan urusan anak-anak, sebagian besar responden menggunakan kombinasi antara bahasa ibu dan bahasa Indonesia. Adapun jumlah responden yang menggunakan kombinasi antara bahasa ibu dan bahasa Indonesia yaitu sebanyak 42 orang atau 38,2 persen. Sedangkan responden yang menggunakan bahasa ibu untuk berkomunikasi urusan keluarga dengan suami atau istri sebanyak 20 orang atau 18,2 persen. Kemudian jumlah paling sedikit berasal dari responden yang menggunakan bahasa Indonesia yaitu berjumlah 6 orang atau 5,5 persen.

Jumlah responden terbanyak yaitu menggunakan kombinasi antara bahasa ibu dan bahasa Indonesia untuk berkomunikasi dengan suami atau istri dalam membicarakan urusan keluarga. Berdasarkan kombinasi tersebut, sebanyak 19 responden hampir selalu mengunakan bahasa ibu. Jumlah tersebut berselisih sedikit dengan responden yang memilih lebih sering menggunakan bahasa Indonesia dari pada bahasa Ibu, yaitu sejumlah 12 orang. Penggunaan bahasa ibu masih sering digunakan dalam ranah rumah tangga, terutama oleh suami dan istri yang merupakan migran tradisional. Penggunaan bahasa ibu dalam komunikasi dengan suami atau istri dirasa lebih santai dan akrab. Berikut percakapan antara suami dan istri dengan menggunakan kombinasi antara bahasa ibu dan bahasa Indonesia.

Bapak : Bu, mas e iki meh wawancara. Sama ibu ya.

Ibu : Lah kok gak sama bapak aja?

Bapak : Ki bapak meh telpon Mas Wardi sek. Sing digoleki sing pendatang luar Semarang.

Ibu : Yawis, sini sama Ibu mas.

(Data Primer, 2016)

3. Bahasa Komunikasi dengan Suami atau Istri untuk Selain Urusan Keluarga

Sama halnya dengan bahasa komunikasi yang digunakan suami atau istri untuk urusan keluarga, bahasa komunikasi yang digunakan suami atau istri untuk selain urusan keluarga juga paling banyak menggunakan kombinasi antara bahasa ibu dan bahasa Indonesia yaitu sebanyak 31,8 persen. Sedangkan penggunaan bahasa ibu dan bahasa Indonesia masing-masing sebnayak 23 orang atau 20,9 persen untuk pengguna bahasa ibu dan 11 orang atau 10 persen untuk pengguna bahasa Indonesia. 
Angka persentase pada tabel di atas menunjukkan bahwa masyarakat sekarang, khususnya yang sudah menikah, sebagian besar menggunakan kombinasi antara bahasa ibu dan bahasa Indonesia, walaupun mereka berasal dari bahasa ibu yang sama. Hal ini semakin menekankan bahwa pergeseran bahasa ibu semakin terasa, terlebih lagi jika melihat tabel di atas pada penggunaan bahasa Indonesia. Pada tabel di atas tertera penggunaan bahasa Indonesia untuk komunikasi dengan suami atau istri untuk selain urusan keluarga sebanyak 11 orang atau 10 persen. Persentase tersebut cukup banyak mengingat bahwa mereka berasal dari bahasa ibu yang sama, tetapi sama sekali tidak menggunakan bahasa ibu untuk berkomunikasi di ranah keluarga.

\section{Bahasa Komunikasi dengan Anak}

Kecenderungan yang terjadi pada zaman sekarang ini yaitu orang tua lebih banyak menggunakan bahasa Indonesia dari pada bahasa daerah untuk berkomunikasi seharihari dengan anaknya. Hal tersebut juga terjadi pada kalangan migran yang berada di Kota Semarang. Dari 63 responden yang berstatus menikah, memiliki anak, dan bahasa ibu responden sama dengan bahasa ibu suami atau istri; sebanyak 32 orang atau 29,1 persen lebih sering menggunakan bahasa Indonesia dari pada bahasa Ibu. Sebagain orang tua beralasan bahwa bahasa Indonesia lebih gampang dan praktis, selain itu juga untuk mengajarkan anaknya agar lancar menggunakan bahasa Indonesia karena di kalangan sekolah bahasa yang digunakan adalah bahasa Indonesia.

Selain itu, sebanyak 11 orang atau 10 persen selalu menggunakan bahasa Indonesia dan masih di angka yang sama yaitu 10 persen memilih lebih sering menggunakan bahasa ibu dari pada bahasa Indonesia ketika berkomunikasi dengan anak. Sedangkan di angka terendah yaitu 9 orang atau 8,2 persen selalu menggunakan bahasa ibu. Bahasa ibu yang digunakan responden untuk berkomunikasi dengan anak yaitu sebagian besar menggunakan bahasa ibu ragam kasar atau ngoko.

Pada awal subbab sudah dijelaskan bahwa responden yang bahasa ibunya sama dengan bahasa ibu dari suami istri lebih sering menggunakan kombinasi antara bahasa ibu dan bahasa Indonesia untuk berkomunikasi dengan anak. Hal tersebut sesuai dengan data kualitatif yang didapatkan peneliti di lapangan.

Ibu : Wid, Mbake ambilkan minum sik ki lho.

Anak : Iya Mah, sik to.

Bapak : Maenan terus kok kerjaane.

Anak : Iya-iya Mah.

(Data Primer, 2016) 
Berbeda dengan itu, responden yang bahasa ibunya berbeda dengan bahasa ibu dari suami atau istri sebagian besar menggunakan bahasa Indonesia untuk berkomunikasi dengan anak. Dari 15 responden yang bahasa ibunya berbeda dengan bahasa ibu dari suami atau istri, sebanyak 11 orang atau 10 persen menggunakan bahasa Indonesia untuk berkomunikasi dengan anak. Jumlah tersebut merupakan pilihan terbanyak dibandingkan pilihan lainnya. Responden beralasan bahwa anak tidak memahami atau menguasai bahasa ibu dari responden ataupun bahasa ibu dari suami atau istri. Kalaupun memahami, persentase pemahamannya masih sedikit. Kebanyakan dari mereka hanya mengerti apa yang diucapkan orang tua mereka dengan bahasa ibu masing-masing, tetapi tidak bisa membalas dengan bahasa yang sama. Hal tersebut sesuai dengan data kualitatif yang didapatkan peneliti di lapangan.

Ibu : Mas, sini bajunya ganti ini udah ibu bawain.

Anak: Bentar bu, ini mau masukin ke gawang (si anak sedang melakukan permainan sepak bola di laptop)

Ibu : Main gamenya entar lagi kan bisa mas. Enggak capek apa habis lomba SSB?

Anak: Enggak to bu.

(Data Primer, 2016)

5. Responden Anak yang Bahasa Ibu Orang Tuanya Berbeda, Bahasa yang Digunakan untuk Komunikasi dengan Ayah

Responden anak yang bahasa ibu orang tuanya berbeda, bahasa yang digunakan untuk komunikasi dengan ayah lebih sering menggunakan bahasa ibu ayahnya yaitu sebanyak satu koma delapan persen. Bahasa lain yang digunakan untuk komunikasi dengan ayahnya yaitu kadang-kadang menggunakan bahasa ibu ayahnya sebanyak nol koma sembilan persen. Dari jumlah di atas, responden hanya menggunakan bahasa ibu ayahnya dengan presentase sedikit dan diperkirakan bahasa ibu mereka sudah bergeser ke bahasa Indonesia.

6. Responden Anak yang Bahasa Ibu Orang Tuanya Berbeda, Bahasa yang Digunakan untuk Komunikasi dengan Ibu

Responden anak yang bahasa ibu orang tuanya sama, bahasa yang digunakan untuk komunikasi dengan ibunya yaitu kadang-kadang menggunakan bahasa ibu dari ibunya. Untuk responden anak mereka hanya menggunakan bahasa ibuny sebanyak satu koma delapan persen saja. Jumlah tersebut sangat sedikit dikarenakan responden lebih sering menggunakan bahasa Indonesia ketika berkomunikasi dengan ibunya. Responden anak 
yang menggunakan bahasa ibu mereka hanya sebagian kecil saja dan itupun tidak semuanya dan intesitasnya hanya sedikit.

7. Responden Anak yang Bahasa Ibu Orang Tuanya Sama, Bahasa Sehari-hari yang Digunakan dengan Orang Tua

Untuk responden anak yang bahasa ibu orang tuanya sama, bahasa sehari-hari yang digunakan untuk berkomunikasi denganorang tuanya yaitu lebih sering menggunakan bahasa ibu sebanyak enam koma empat persen. Selain itu ada juga responden anak yang kadang-kadang menggunakan bahasa ibu mereka sebanyak tiga koma enam persen. Responden anak yang selalu menggunakan bahasa ibu mereka cukup sedikit yaitu hanya sebanyak dua koma tujuh persen saja. Selain menggunakan bahasa ibu untuk berkomunikasi, responden anak juga ada yang tidak pernah menggunakan bahasa ibunya untuk berkomunikasi dengan orang tuanya, tapi jumlah sangat sedikit jika dibandingkan dengan yang menggunakan bahasa ibunya yaitu hanya satu koma delapan persen. Jumlah tersebut menunjukan bahawa jika bahasa ibu kedua orang tuanya sama mereka cenderung menggunakan bahasa ibunya untuk berkomunikasi, namun jika bahasa ibu orang tuanya berbeda mereka akan jarang menggunakan bahasa ibunya untuk berkomunikasi. Penjelasan mengenai hal tersebut dapat dilihat dalam tabel berikut.

8. Ragam Bahasa yang Digunakan untuk Komunikasi dengan Orang Tua Ragam bahasa responden anak yang digunakan untuk berkomunikasi dengan orang tua menggunakan bahasa ibu ragam halus, ragam kasar, dan kombinasi dari keduanya. Untuk presentasi paling banyak anak menggunakan bahasa ibu ragam kasar (ngoko) unruk berkomunikasi dengan orang tua, yaitu sebanyak sepuluh persen. Presentase tersebut cukup banyak jika dibanding dengan anak yang menggunakan bahasa ibu ragam halus (krama), yaiutu hanya dua koma tujuh persen. Dari jumlah presentase tersebut dapat dilihat bahwa dalam berkomunikasi dengan orang tua, anak lebih sering menggunakan ragam kasar. Responden anak juga menggunakan kombinasi dari keduanya lebih sering menggunakan ragam halus, tapi jumlah pengguna bahasa ini hanya sedikit saja yaitu nol koma sembilan persen.

9. Bahasa Ibu yang Dikuasi Merupakan Hasil Belajar dari

Bahasa ibu yang dikuasai oleh responden anak paling banyak merupakan hasil belajar dari orang tua yaitu sebanyak 11,8 persen. Hal itu karena memang orang tua merupakan sekolah pertama bagi anak, sehingga dalam berkomunikasi pun anak belajar pertama kali dengan orang tuanya. Selain dari orang tua, anak juga belajar bahasa ibu dari 
lingkungan sekolah yaitu sebanyak satu koma delapan persen. Sekolah merupakan tempat belajar bagi anak selain di rumah, sehingga dari sekolah juga anak bisa belajar bahasa ibunya.

\section{Simpulan}

Pada ranah keluarga, suami atau istri yang bahasa ibunya sama dengan bahasa ibu dari pasangan (suami atau istri), lebih sering menggunakan kombinasi antara bahasa ibu dan bahasa Indonesia untuk berkomunikasi dalam hal urusan keluarga maupun selain urusan keluarga, masing-masing angka persentasenya yaitu 38,2 persen dan 31,8 persen. Adapun bahasa yang digunakan untuk berkomunikasi dengan anak bagi migran yang bahasa ibunya sama dengan bahasa ibu suami/istri yaitu sebagain besar lebih sering menggunakan bahasa Indonesia dari pada bahasa ibu. Bagi migran yang bahasa ibunya berbeda dengan bahasa ibu pasangan (suami/istri), sebagian besar selalu menggunakan bahasa Indonesia untuk berkomunikasi dengan anak.

Sementara itu, pada ranah keluarga bagi anak, baik yang bahasa ibu orang tuanya berbeda ataupun sama, sebagian besar menggunakan bahasa ibu untuk berkomunikasi dengan orang tua mereka. Ragam bahasa ibu yang sering digunakan yaitu ragam kasar atau ngoko.

\section{Daftar Pustaka}

Amar, Rahim. 2004. "Pergeseran dan Pemertahanan Bahasa" dalam http://dlop.gov.my/dlop98/pb099jurai.htm.

Borbely, Anna. 2000. "The Process and the Factors of Language Shift and Maintenance: A Sociolinguistics Research in the Romanian Minority in Hungary". http://e-lib.rss.cz

Borin, Lars. 2009. Linguistic resources for the languages of the world. Språkbanken, Dept. of Swedish Language, University of Gothenburg GF summer school, 26 August.

Chaer, Abdul dan Leonie Agustina. 2010. Sosiolinguistik: Perkenalan Awal. Jakarta: Rineka Cipta.

Fasold, Ralp. 1984. Sociolinguistics of Society. New York: Basil Blackwell.

Jamzaroh., Siti, dkk, 2012. "Pergeseran Bahasa (Language Shifting) dalam Keluarga BanjarBanjar di Kalimantan Selatan. Balai Bahasa Kalimantan Selatan.

Mantra, Ida Bagoes. 2015. Demografi Umum, Cetakan XVII. Yogyakarta: Pustaka Pelajar.

Mardikantoro, Hari Bakti. 2007. "Pergeseran Bahasa Jawa dalam Ranah Keluarga pada Mayarakat Multibahasa di Wilayah Kabupaten Brebes" dalam Humaniora, volume 19/I : 43-44. 
Mbete, Aron Meko. 2003. "Bahasa dan Budaya Lokal Minoritas: Asal Muasal, Ancaman, dan Ancangan Pemberdayaan dalam Rangka PIP Kebudayaan Universitas Udayana". Orasi Ilmiah Pengukuhan Guru Besar Unud, Bali.

Musgrave, Simon and John Hajek. 2010. "Sudanese Languages in Melbourne: Linguistic Demography and Language Maintenance". Selected Papers from the 2009 Conference of the Australian Linguistic Society, edited by Yvonne Treis \& Rik De Busser. http://www.als.asn.au.

Setyawan, Aan. 2011. "Bahasa Daerah dalam Perspektif Kebudayaan dan Sosiolinguistik: Peran dan Pengaruhnya dalam Pergeseran dan Pemertahanan Bahasa. International Seminar Languuge Maintenance and Shift, 2 Juli.

Sumarsono. 2013. Sosiolinguistik, cetakan IX. Yogyakarta: Pustka Pelajar.

Wijana, I Dewa Putu. 2013. Sosiolinguistik: Kajian Teori dan Analisis. Cetakan V. Yogyakarta: Pustaka Pelajar.

Yuliawati, Susi. 2008. "Situasi Kebahasaan di Wilayah Pangandaran:Suatu Kajian Sosiolinguistik tentangPergeseran dan Pemertahanan Bahasa" Thesis S2 Program Studi Linguistik Unpad Bandung. 